\title{
Country-specific cost-effectiveness of early intervention with budesonide in mild asthma
}

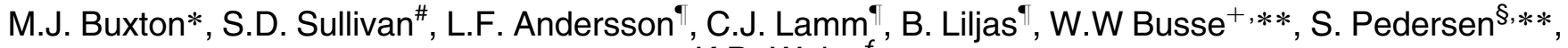 \\ K.B. Weiss ${ }^{f}$
}

Country-specific cost-effectiveness of early intervention with budesonide in mild asthma. M.J. Buxton, S.D. Sullivan, L.F. Andersson, C.J. Lamm, B. Liljas, W.W Busse, S. Pedersen, K.B. Weiss. (C) ERS Journals Ltd 2004.

ABSTRACT: Early intervention with budesonide is an effective strategy for mild persistent asthma, which has been shown to provide additional clinical benefits at a low incremental cost using USA cost data. The present authors analysed whether this strategy would be cost-effective using cost data for other countries.

Based on the 3-yr prospective, randomised, double-blind inhaled Steroid Treatment As Regular Therapy (START) in early asthma study (comparing budesonide and placebo combined with usual asthma therapy), the cost-effectiveness was estimated separately for eight different countries, from both healthcare payer and societal perspectives, of adding budesonide to usual asthma therapy. Local unit costs were applied to data for the total trial population. Incremental cost-effectiveness ratios (ICER) were estimated as cost per symptom-free day (SFD) gained.

Budesonide increased SFDs by an average of 14.1 days annually. From a healthcare payer perspective, budesonide would reduce the total cost of asthma care in Australia. In Sweden, Canada, France, Spain, UK, China and the USA, the ICER ranged from US\$2.4-11.3 per SFD. From a societal perspective, budesonide would be cost-saving in Australia, Canada and Sweden.

In conclusion, for countries where costs with budesonide are higher, the policy implication has to be determined by that health system's willingness to pay for an additional symptom-free day. However, where budesonide therapy increases symptomfree days and reduces total costs, the policy conclusion clearly favours early intervention.

Eur Respir J 2004; 24: 568-574.
*Health Economics Research Group, Brunel University, Uxbridge, UK. ${ }^{\#}$ Depts of Pharmacy and Health Services, University of Washington, Seattle, WA, ${ }^{+}$University of Wisconsin, Madison, WI, ${ }^{f}$ The Midwest Center for Health Services and Policy Research, Hines VA Hospital, Hines, and the Center for Healthcare Studies, Northwestern University Medical School, Chicago, IL, USA. "AstraZeneca R\&D, Lund, Sweden. ${ }^{\S}$ Dept of Paediatrics, Kolding Hospital, Kolding, Denmark.

Correspondence: M. Buxton, Health Economics Research Group, Brunel University, Uxbridge, Middlesex, UB8 3PH, UK. Fax: 441895269708

E-mail: martin.buxton@brunel.ac.uk

Keywords: Budesonide, cost-effectiveness, early intervention, inhaled Steroid Treatment As Regular Therapy in early asthma, international

Received: September 252003

Accepted after revision: June 162004

**On behalf of the inhaled Steroid Treatment As Regular Therapy (START) Steering Committee.

This study was fully funded by AstraZeneca R\&D, Lund, Sweden. The sponsors of the study had no role in the design, analysis and interpretation of the results of this costeffectiveness study, with the exception of the company co-authors who participated in all aspects of the study. All investigators had free and unlimited access to the raw data and statistical reports.
The inhaled Steroid Treatment As Regular Therapy (START) in early asthma study demonstrated the effective-

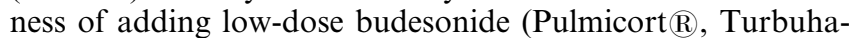
ler () ) to usual asthma therapy in patients with mild persistent asthma. The trial included $>7,000$ patients from 32 countries. Budesonide significantly reduced the risk of a first severe asthma-related event, reduced hospital days and emergency room visits and increased the number of symptom-free days (SFDs) [1, 2]. Early intervention with budesonide provided these clinical benefits at a low incremental cost, based on an analysis of data from all patients in this international trial, where patient-specific resource use was valued using a price vector of unit costs for the USA [2].

However, if economic analyses are to influence policy decisions, it is important to establish whether the same policy conclusions about cost-effectiveness can be drawn for other countries involved in the trial and for other countries to which the policy implications might be extrapolated. Relative prices vary significantly between healthcare systems in different countries [3], and a number of different methods may be used to reflect the variation in relative prices [4].

The current report analyses the extent to which the different relative unit costs in particular countries may change the policy conclusions that budget holders, formulary committees or reimbursement agencies may draw from the study.

\section{Methods}

The design of the START study and the details of the methods employed in the health-economic analysis have previously been reported in full $[2,5,6]$. A brief review of the general design and methods, as well as details of those specific to the analysis in the present report, are provided below. 


\section{Overview of the START trial}

In a double-blind trial, 7,165 patients, aged 5-66 yrs, with mild persistent asthma (diagnosed $\leqslant 2$ yrs) and no previous regular treatment with inhaled corticosteroids were randomised to receive low-dose budesonide Turbuhaler $\mathbb{R}$ q.d. (200 $\mu \mathrm{g}$ for children $<11 \mathrm{yrs}$ and $400 \mu \mathrm{g}$ for others) or placebo for $3 \mathrm{yrs}$, in addition to their usual asthma medication. There were no restrictions regarding type or dose of concurrent asthma therapy and inhaled corticosteroids that could be added in either arm. Thus, in this pragmatic study, the placebo arm approximates usual asthma therapy, as would be practised in the various participating countries $[1,5]$.

\section{Effectiveness and resource data collection}

SFDs, defined as a $24-\mathrm{h}$ period with no asthma symptoms, were pre-defined as the primary measure of effectiveness for the economic analysis [2, 6-8]. Healthcare resource use data were collected prospectively, and comprised the costs from a healthcare payer perspective. The number of days a patient missed work due to asthma (and for children, the number of days they missed school or their caregiver missed work) were self-reported and are included in the analysis from the societal perspective. For patients who dropped out of the trial, both resource use and effectiveness data were linearly extrapolated to the full 3-yr study period.

\section{Unit-cost estimation}

In the primary analysis of cost-effectiveness, resource use was valued using appropriate USA unit cost data [2]. In the present analysis, relevant unit costs were obtained for seven additional countries (Australia, Canada, China, France, Spain, Sweden and the UK). Together, the eight countries represented $\sim 35 \%$ of the total trial population. These countries were chosen for the following reasons: to reflect a range of expected cost profiles; to take into account those countries where cost-effectiveness information is seen as playing an increasingly important role in the determination of healthcare policy and coverage; and subject to a constraint of access to appropriate and robust cost data.

The precise sources of the unit cost data varied by country, but, wherever possible, the most appropriate locally derived and published (or publicly available) sources were used. Drawing on local expertise, relevant cost estimates were obtained from each country for the various items of resource use measured in the trial. Where necessary, these costs were adjusted using appropriate national price indices to a common price basis of 1999. The cost of a day's absence from work was calculated using the human capital approach, and absences from school were given the same value as absences from work. For each country, details of the sources and values for each of the main resource use items are shown in table 1 [9-43].

\section{International comparisons}

The figures obtained were provided in local currency units, which are, of course, the most relevant to local decision-makers. For the purpose of comparison between countries, the purchasing power parity (PPP) method was used as the appropriate basis for comparison [4]. Local prices were converted into a common basis in 1999 US dollars using gross domestic product (GDP) PPP exchange rates [44]. Use of simple exchange rate conversion factors, reflecting the average official/market exchange rate between the local currency and US dollars during the year in question would have been more familiar to readers, but would not have taken account of the relative internal purchasing power of the local currency. The latter factor is reflected in overall GDP PPPs, which reflect what different currencies will purchase in terms of goods and services in the domestic market relative to what a dollar would purchase in the USA [45].

\section{Cost-effectiveness}

Using resource use data for all patients, regardless of the country in which they were recruited, patient-specific costs were calculated for each patient in the budesonide and usual asthma therapy arms using each of these eight price vectors as eight separate analyses. Then, for each price vector, incremental cost-effectiveness ratios (ICERs) were calculated as the difference in costs divided by the difference in SFDs. The same analytical methods as originally presented using the USA unit cost vector were used here [2]. Separate ICERs were calculated for the healthcare payer perspective and for the societal perspective. Costs and outcomes were both discounted at $3 \%$, reflecting the accepted international reference case [46]. Cases of dominance (where there were more SFDs and lower costs) are represented as negative ICERs to facilitate the representation of the $95 \%$ confidence interval around the point estimate.

\section{Results}

Baseline characteristics of trial participants have been described by PAUWELs et al. [1]. In short, the mean age was $24 \mathrm{yrs}, 54 \%$ were female, the mean pre-bronchodilator FEV1 was $86.4 \%$ predicted and the average duration of asthma was 0.7 yrs (table 2). Early intervention with budesonide reduced the hazard rate for the primary clinical endpoint of severe asthma-related events (defined as an event requiring hospitalisation or emergency treatment due to worsening of asthma or death due to asthma) by $44 \%(\mathrm{p}<0.001)$. On average, budesonide-treated patients experienced 14.1 more SFDs per year $(\mathrm{p}<0.001)$, had $69 \%$ fewer hospital days $(\mathrm{p}<0.001)$ and $67 \%$ fewer emergency room visits $(\mathrm{p}<0.05)$ compared with those who received only usual asthma therapy. Quantities of resource use by main category are presented in table 3 .

Table 4 presents the ICERs in local currency, the regular exchange rates and the GDP PPP rates by country used for comparison between countries. Negative ICERs here show that early intervention with budesonide for Australia would be dominant from both the healthcare payer and societal perspectives, and would also be dominant for Canada and Sweden but from the societal perspective only.

The ratios between the PPP-adjusted rate and the exchange rate are fairly similar for France, UK and Sweden (1.06, 1.17 and 1.18 , respectively); for each of these countries, internal price levels mean that the exchange rate comparison with the dollar overstates the internal purchasing power of the currencies. The ratios for Australia, Spain and Canada are $0.87,0.84$ and 0.80 , respectively; for these, the exchange rates understate the internal purchasing power. The extreme case is China, with a ratio of 0.22 , indicating that the internal purchasing power of the Yuan is more than four times that implied by the exchange rate.

Figures 1 and 2 show the PPP-adjusted ICERs for each country's set of relative prices. From the healthcare payer 


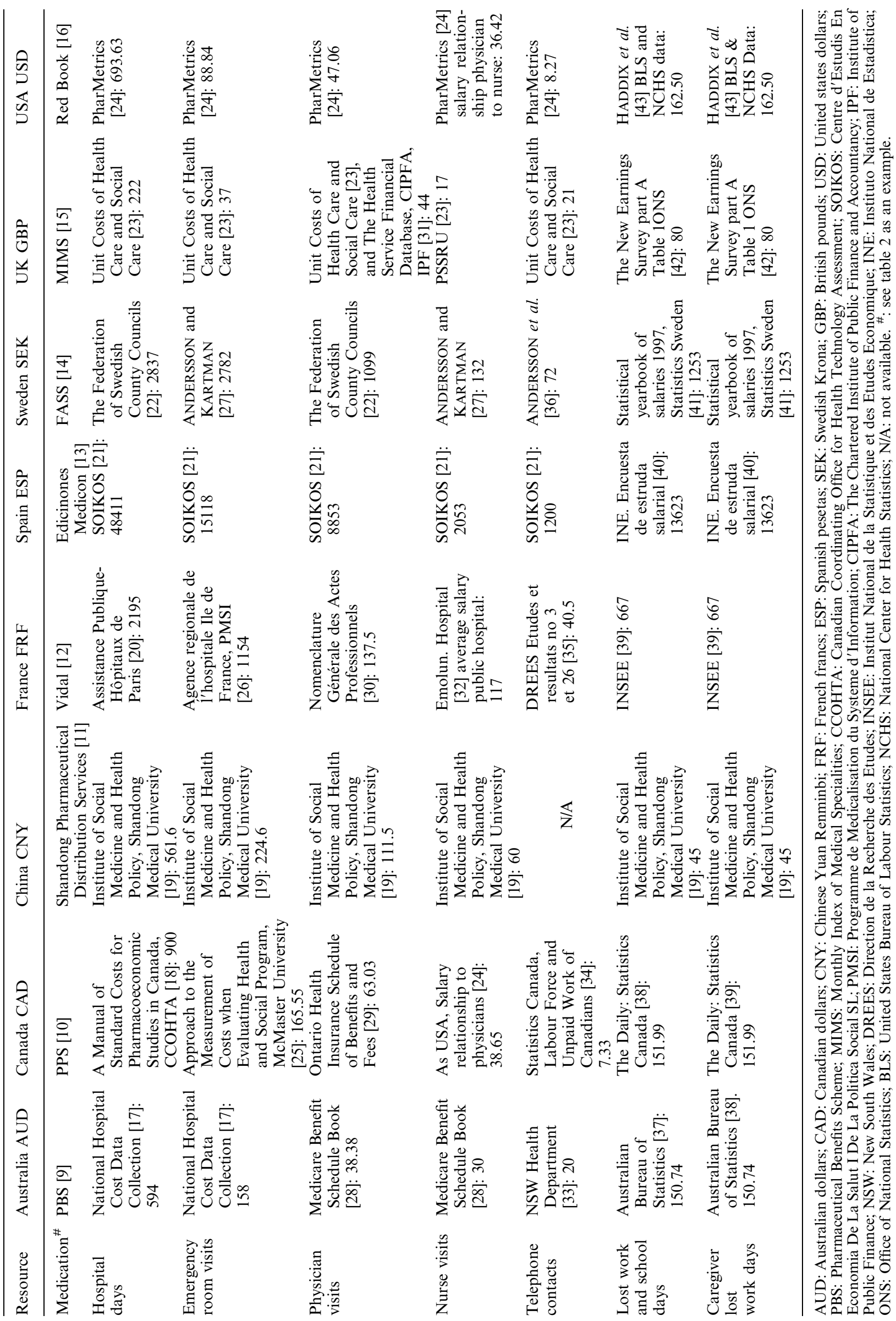


Table 2.-Demographics, clinical characteristics and drug use at baseline for usual asthma therapy plus placebo or budesonide

\begin{tabular}{|c|c|c|}
\hline Variable & Placebo & Budesonide \\
\hline Age yrs & $24.3 \pm 14.8$ & $23.7 \pm 14.6$ \\
\hline \multicolumn{3}{|l|}{ Distribution } \\
\hline $5-10$ yrs & 27.3 & 27.8 \\
\hline $11-17$ yrs & 16.3 & 17.8 \\
\hline$>18$ yrs & 56.4 & 54.4 \\
\hline Sex female & 54.0 & 54.2 \\
\hline SFDs in past 14 days & $9.05 \pm 3.76$ & $9.03 \pm 3.79$ \\
\hline \multicolumn{3}{|l|}{ Distribution } \\
\hline 0 days & 8.8 & 8.6 \\
\hline 1-3 days & 34.6 & 36.3 \\
\hline 4-7 days & 35.8 & 33.5 \\
\hline$>7$ days & 20.8 & 21.6 \\
\hline \multicolumn{3}{|l|}{ Smoking status $\#$} \\
\hline Active & 20.3 & 20.5 \\
\hline Passive & 30.1 & 28.0 \\
\hline Never & 49.6 & 51.5 \\
\hline \multicolumn{3}{|l|}{ Duration of asthma } \\
\hline$<3$ months & 35.7 & 36.8 \\
\hline $3-<6$ months & 13.3 & 14.4 \\
\hline $6-<12$ months & 16.9 & 15.5 \\
\hline$>1 \mathrm{yr}$ & 34.1 & 33.3 \\
\hline Mean duration yrs & 0.7 & 0.7 \\
\hline Pre-bronchodilator FEV1 \% pred & $86.6 \pm 13.9$ & $86.3 \pm 13.9$ \\
\hline \multicolumn{3}{|l|}{ Drug use at study start } \\
\hline Inhaled CS & 5.1 & 4.9 \\
\hline Oral/systemic CS & 4.5 & 4.0 \\
\hline Short-acting $\beta_{2}$ agonist & 64.6 & 63.5 \\
\hline Long-acting $\beta_{2}$ agonist & 3.1 & 2.6 \\
\hline Xanthine & 11.4 & 11.4 \\
\hline Cromone & 7.5 & 7.9 \\
\hline Leukotriene modifier & 0.1 & 0.1 \\
\hline Other & 11.9 & 12.6 \\
\hline None & 24.3 & 24.6 \\
\hline
\end{tabular}

Data are presented as mean \pm SD or $\%$. SFD: symptom-free day; FEV1: forced expiratory volume in one second; CS: corticosteroids; $\%$ pred: per cent predicted. ${ }^{\#}$ : active denotes current or previous smoker, passive denotes passive but not active smoker, never denotes neither active nor passive smoker; ": percentage of patients receiving additional antiasthma therapy on the 6 weeks preceding the entry visit. $\mathrm{N}=3,568$ for placebo and $n=3,597$ for budesonide.

perspective, there are notable differences between countries; the USA being at the upper end of the range, with overall results very similar to China. At the other extreme is Australia, where early intervention with budesonide is dominant, providing additional SFDs whilst reducing healthcare costs by US\$21 per patient per year $(p<0.05)$. For Sweden and Canada, the ICERs would be relatively small from the healthcare payer perspective and dominant from the societal perspective, where the intervention would generate savings of US\$48 $(\mathrm{p}=0.01)$ and US $\$ 44(\mathrm{p}<0.1)$ per patient per year, respectively. Spain, France and the UK lie in the middle of the range.

\section{Discussion}

There is no clear agreement on how best to represent the cost-effectiveness results from a large trial that includes patients from many countries in order to facilitate appropriate interpretation of the results [47-52]. The original analysis of the cost-effectiveness of early intervention with low-dose budesonide by the present authors concluded that the ICER (in terms of incremental cost per SFD) seemed acceptably low when analysed in terms of USA unit costs [2]. The present study shows how the cost-effectiveness of early intervention with budesonide varies with the different unit costs that apply to healthcare systems in different countries. With the exception of the analysis with Chinese unit costs, from the societal perspective these analyses demonstrate more favourable ICERs than the original analysis with USA unit costs. For some countries there is an added cost for the additional clinical benefits received, whereas other countries show cost savings by using budesonide as early intervention. For those countries where there was an added cost, the ICER ranged from US\$2.4-11.3 (healthcare perspective) and US\$0.1-9.2 (societal perspective).

The current study is the first to measure incremental cost per SFD for early intervention in mild asthma. Earlier studies were of mild-to-moderate and moderate-to-severe asthma, where the potential for cost-offsets is greater and, therefore, the ICERs were likely to be lower. RUTTEN-VAN MöLKEN et al. [53] calculated an ICER of US\$5.35 per SFD (healthcare perspective) for the addition of inhaled corticosteroids (ICS) in moderate-to-severe asthma and/or chronic obstructive pulmonary disease. Investigating the impact of an inner-city based education programme for children with asthma, SULLIVAN et al. [54] estimated an ICER of US\$9.20 per SFD (healthcare perspective). Furthermore, PALTIEL et al. [55] reported an ICER of US\$7.50 per SFD (societal perspective) for the addition of ICS in mild-to-moderate asthma.

Whether these ICERs provide good value for money or not will depend on the local situation. However, it would be helpful to compare these results to those in other therapeutic areas. One of the difficulties is that the SFD is a diseasespecific measure of effectiveness. An effectiveness measure that can be used in any disease area is the quality-adjusted life-year (QALY). CHAPMAN et al. [56] found 14 studies on economic evaluations of the respiratory system using QALYs. For these studies, the median ICER was US\$40,500 per QALY. There is an ongoing debate about what cost per

Table 3. - The 3-yr healthcare resource use rates by treatment group

\begin{tabular}{lccc}
\hline Resource & Usual asthma therapy & Budesonide ${ }^{+}$ & Overall difference $^{\#}(\%$ difference $)$ \\
\hline Hospital days & $0.55 \pm 0.12$ & $0.17 \pm 0.03$ & $-0.38 \pm 0.12^{* * *}(-69)$ \\
Emergency visits & $0.09 \pm 0.02$ & $0.03 \pm 0.01$ & $-0.06 \pm 0.03^{*}(-67)$ \\
Physician visits & $2.03 \pm 0.07$ & $1.30 \pm 0.05$ & $-0.73 \pm 0.09^{* * *}(-36)$ \\
Nurse visits & $0.13 \pm 0.02$ & $0.08 \pm 0.01$ & $-0.05 \pm 0.02^{* *}(-38)$ \\
Telephone contacts & $0.64 \pm 0.04$ & $0.42 \pm 0.03$ & $-0.22 \pm 0.05^{* * *}(-34)$ \\
Work and school days lost & $5.16 \pm 0.35$ & $3.22 \pm 0.22$ & $-1.94 \pm 0.42^{* * *}(-37)$ \\
Caregiver work days lost & $0.71 \pm 0.10$ & $0.53 \pm 0.08$ & $-0.18 \pm 0.13(-25)$ \\
\hline
\end{tabular}

Data are presented as mean \pm SE. ${ }^{\#}$ : difference=budesonide-usual asthma therapy; $\%$ difference $=100 \times($ budesonide-usual asthma therapy)/usual asthma therapy; ${ }^{+}: \mathrm{n}=3,568 ; \uparrow: \mathrm{n}=3,797$; Statistical test of difference: stratified Wilcoxon test for hospital days and stratified $\mathrm{z}$-test for other items; Tests were two-tailed; *: $\mathrm{p}<0.05 ; * *: \mathrm{p}<0.01 ; * * *: \mathrm{p}<0.001$. 
Table 4.- Incremental cost-effectiveness ratios (ICERs) in local currency, the exchange rates and the gross domestic product purchasing power parity (PPP) rates

\begin{tabular}{|c|c|c|c|c|c|}
\hline Country & Local currency & $\begin{array}{c}\text { Healthcare payer } \\
\text { perspective ICER }(95 \% \mathrm{CI})\end{array}$ & $\begin{array}{l}\text { Societal perspective } \\
\text { ICER }(95 \% \mathrm{CI})\end{array}$ & $\begin{array}{c}\text { Exchange rates } \\
1999\end{array}$ & $\begin{array}{l}\text { PPP rates } \\
1999\end{array}$ \\
\hline USA & US Dollars & $11.3(8.6-14.9)$ & $3.7(0.1-8.0)$ & 1 & 1 \\
\hline Australia & Australian Dollars & $-2.2(-4.3--1.0)$ & $-10.8(-15.7--6.2)$ & 1.5 & 1.3 \\
\hline Canada & Canadian Dollars & $4.1(2.0-6.5)$ & $-3.7(-7.9-0.5)$ & 1.5 & 1.2 \\
\hline China & Chinese Yuan & $19.6(12.5-28.5)$ & $16.5(9.2-25.5)$ & 8.3 & 1.8 \\
\hline France & French Francs & $34.2(24.6-46.6)$ & $0.6(-16.3-18.9)$ & 6.2 & 6.6 \\
\hline Spain & Spanish Pesetas & $802(615-1052)$ & $159(-117-470)$ & 156.2 & 130.6 \\
\hline Sweden & Swedisk Krona & $23.9(11.6-38.9)$ & $-33.5(-59.7--7.1)$ & 8.3 & 9.8 \\
\hline UK & British Pounds & $4.7(3.7-6.1)$ & $0.9(-0.7-2.6)$ & 0.6 & 0.7 \\
\hline
\end{tabular}

Number of randomised patients: USA n=895; Australia n=85; Canada $n=114$; China $n=869$; France $n=114$; Spain $n=291$; Sweden $n=120$; UK n=39; The currency of France and Spain is now Euro; Exchange rates were set to 1 Euro equals FRF6.55957 and ESP166.386, respectively.

QALY constitutes good value for money. It has been shown that the National Institute for Clinical Excellence (NICE) in the UK seems to be willing to fund interventions with a cost per QALY $<£ 30,000$ (equivalent to US\$47,000, exchange rate on April 2, 2003) [57] and US\$50,000 is commonly referred to as the acceptable threshold in the USA [46]. In the study by PALTIEL et al. [55], one of the very few studies in asthma which used both QALYs and SFDs, the ICER of US\$7.50 per SFD translated into an ICER of US $\$ 13,500$ per QALY. Thus, their estimate of US\$7.50 is consistent with an incremental cost per QALY well within the limits of what appears to be acceptable in the UK and the USA. If this same relationship between cost per SFD and cost per QALY applies to ICERs for budesonide as early intervention, it too would appear to provide good value for money (at least for these two countries).

It is widely accepted that, in comparisons between countries such as those made in this study, it is more appropriate to use GDP PPP conversion rates rather than regular exchange rates [4]. For the countries studied here, the differences between the two sets of rates were substantial, with ratios of PPP rates to exchange rates ranging $1.18-0.22$. The extreme case was that of China, where the PPP rate reflects a low-wage economy. These different ratios emphasise the impact of the decision to use PPP rates rather than exchange rates when comparing the ICERs, on the basis that the former more accurately reflect the opportunity cost of the resources within the economy [5].

The present study shows that there can be a complex pattern of differences in ICERs between countries when local

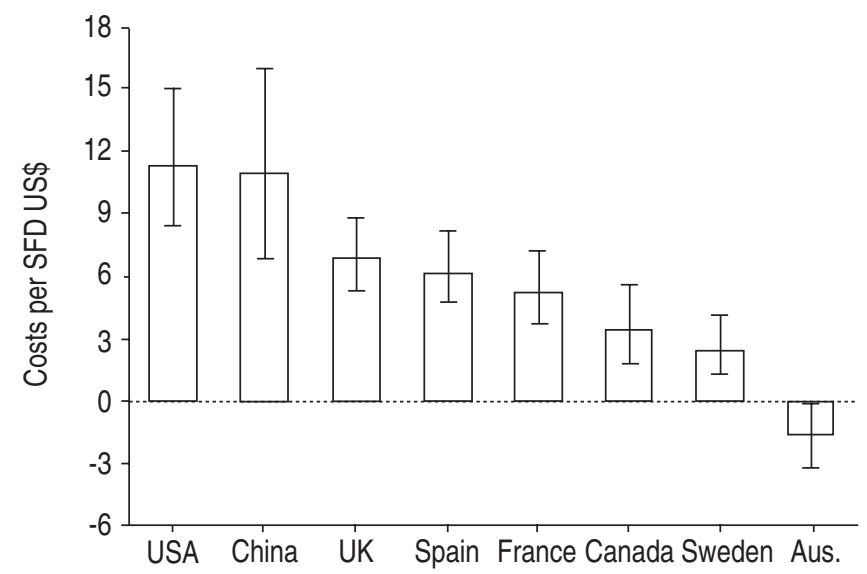

Fig. 1.-Purchasing power parity-adjusted incremental cost-effectiveness ratios for each country's set of relative prices from the healthcare payer perspective. Data are presented as 95\% confidence intervals around the point estimate. SFD: symptom-free day; Aus.: Australia. relative prices are taken into account and that data based on one initial set of unit costs will not necessarily be generalisable. Whilst it shows that the absolute values of the ICERs are fairly sensitive to relative price structures, it is more difficult to judge whether the policy implications are similarly sensitive. The policy implications depend on a judgement made nationally or locally as to what is an acceptable price to pay for an additional health benefit, in this case an additional SFD. Whilst the use of GDP PPP-adjusted exchange rate comparisons provides a degree of comparability between the figures (in each case the generalised GDP opportunity cost of US\$1.00 spent on this therapy is approximately the same), there is no reason to presume that willingness to pay for an SFD will be the same in each country. Willingness to pay may vary between systems with different social priorities and indeed between decision-makers within them. The current authors know of no systematic attempt to compare these values between countries, although the perceived threshold values for an acceptable cost per quality-adjusted survival (as discussed previously) may provide some indication of relative willingness to pay for health gains.

The current analysis takes full account of locally relevant unit costs of resources in eight different countries and, thus, represents a step towards understanding national differences in cost-effectiveness of this therapy. However, the authors know that the pattern and level of resource use for the treatment of asthma in the usual-care setting will differ between countries (reflecting a range of factors, including availability of healthcare resources, culture, history, etc.), and

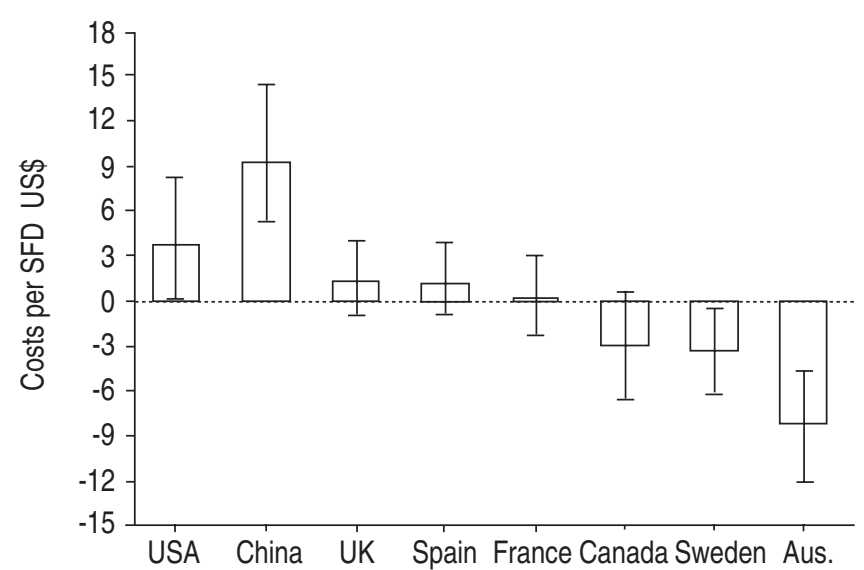

Fig. 2. - Purchasing power parity-adjusted incremental cost-effectiveness ratios for each country's set of relative prices from the societal perspective. Data are presented as 95\% confidence intervals around the point estimate. SFD: symptom-free day; Aus.: Australia. 
this has not been taken into account in the present analysis. Additionally, the current analysis does not take into account the possibility that the incremental benefit might differ between countries as a result of differences in relative clinical effectiveness between budesonide and usual asthma therapy, or between perceptions and behavioural differences in what constitutes a SFD. The present study was not powered to permit subgroup analysis by country. In a study with fewer countries, it might have been possible to estimate countryspecific effects or to adjust results using proxy variables such as GDP or other factors that might be found to influence cost-effectiveness.

\section{Conclusions}

Early intervention with budesonide has been shown to be an effective therapy in patients with mild persistent asthma, significantly improving symptom-free days, and reducing hospitalisations and emergency room visits. The current report shows that, in some of the analysed countries, these benefits are achieved at a lower total cost (i.e. budesonide therapy is dominant), whereas in other countries it comes at a small incremental cost. This analysis emphasises that the incremental costs will vary with local unit costs (prices) and that care should be taken when extrapolating results based on one country's relative prices to other countries. Where the incremental cost-effectiveness ratio is positive, however high or low, the policy implication can only be judged locally, on the basis of the health system's willingness to pay for an additional symptom-free day. However, in those situations where budesonide provides more health benefits at a lower cost, the policy conclusion is unambiguously in favour of early intervention.

\begin{abstract}
Acknowledgements. W.W. Busse and S. Pedersen contributed on behalf of the START Steering Committee (members: B. Andersson, W.W. Busse, L.G. Carlsson, Y.Z. Chen, C.J. Lamm, P.M. O'Byrne, S. Pedersen, R.A. Pauwels and W.C. Tan). The authors would like to thank A-S. Hörstedt for statistical programming and $E$. Runnerström and U. Farmängen for monitoring the clinical trial. The authors are grateful to $\mathbf{J}$. Hall, M. Rolnick, Q. Meng, J. Rovira, C. Sullivan, and Medical Technology Assessment and Policy (MEDTAP) International, London for assistance in obtaining local unit costs.
\end{abstract}

\section{References}

1. Pauwels RA, Pedersen S, Busse WW, et al. Early intervention with budesonide in mild persistent asthma: a randomised double-blind trial. Lancet 2003; 361: 1071-1076.

2. Sullivan SD, Buxton M, Andersson LF, et al. Costeffectiveness analysis of early intervention with budesonide in mild persistent asthma. J Allergy Clin Immunol 2003; 112: 1229-1236.

3. Schulman K, Burke J, Drummond M, et al. Resource costing for multinational neurologic clinical trials: methods and results. Health Economics 1998; 7: 629-638.

4. Gosden TB, Torgerson DJ. Converting international cost effectiveness data to UK prices. BMJ 2002; 325: 275-276.

5. Pauwels RA, Busse WW, O'Byrne RM, et al. The inhaled Steroid Treatment As Regular Therapy in early asthma (START) study: rational and design. Control Clin Trials 2001; 22: 5-19.

6. Sullivan SD, Liljas B, Buxton M, et al. Design and analytic considerations in determining the cost-effectiveness of early intervention in asthma from a multinational clinical trial Control Clin Trials 2001; 22: 20-37.

7. National Institutes of Health. National Asthma Education and Prevention Program Task Force on the Cost Effectiveness, Quality of Care, and Financing of Asthma Care. NHLBI, No. 55-807. Washington DC, National Institutes of Health, 1996.

8. Sullivan SD, Elixhauser A, Buist AS, Luce BR, Eisenberg J, Weiss KB. National Asthma Education and Prevention Program working group report on the cost effectiveness of asthma care. Am J Respir Crit Care Med 1996; 154: 3 Pt 2, S84-S95.

9. Pharmaceutical Benefits Scheme (PBS). Canberra, Australia, 2000.

10. PPS Pharma Publication. Moncton, Total Publishing Systems Inc., January 2000.

11. Shandong Pharmaceutical Distribution Services. Shandong, China, 2000.

12. Vidal, Paris, France, 2000.

13. Ediciones Medicon. Madrid, Spain, 2000.

14. Pharmaceuticals in Sweden. Stockholm, Linfo, Läkemedelsinformation AB, 2000

15. Monthly Index of Medical Specialities (MIMS). London, Haymarket Publishing Ltd., 2000.

16. Drug Topics Red Book. Montvale, Medical Economics, 2000 .

17. National Hospital Cost Data Collection, 1998-1999. Department of Health, Canberra, Australia, 2000.

18. Jacobs P, Bachynsky J, Hall E. A Manual of Standard Costs for Pharmacoeconomic Studies in Canada. Ottawa, Canada, Canadian Coordinating Office for Health Technology Assessment (CCOHTA), 1995.

19. Institute of Social Medicine and Health Policy, Shandong Medical University, Shandong, China, 2000.

20. Assistance Publique-Hôpitaux de Paris. Paris, France, 1995.

21. Centre d'Estudis En Economia De La Salut I De La Politica Social SL (SOIKOS). Base de datos de costes sanitaros, Actualization de 1999, Barcelona, Spain. www.soikos.com 1999.

22. Costs per inpatient: number of days, physician visits, etc. in 1993. Stockholm, The Federation of Swedish County Councils, 1995.

23. Personal Social Services Research Unit (PSSRU). Unit Cost of Health and Social Care. Netten A, Dennett J, Knight J, eds. PSSRU, University of Kent at Canterbury, Canterbury, UK. www.pssru.ac.uk. 2000.

24. PharMetrics Integrated Outcomes Database. 1999.

25. Approach to the Measurement of Costs when Evaluating Health and Social Program. McMaster University, Hamilton, Canada, November 1995.

26. Agence regionale de l'hospitale Ile de France, Paris, France. Programme de Medicalisation du Systeme d'Information (PMSI), 1998

27. Andersson F, Kartman B. The Cost of Angina Pectoris in Sweden. Pharmaco Economics 1995; 7: 233-244.

28. Medicare Benefit Schedule Book (November 1998). Dept of Health, Canberra, Australia, 1999.

29. Ontario Health Insurance Schedule of Benefits and Fees (February 1, 1998. Revised: April, 1999). Toronto, Canada, 1999.

30. Nomenclature Générale des Actes Professionnels (1998). Paris, France, 1999.

31. The Health Service Financial Database. The Chartered Institute of Public Finance and Accountancy (CIPFA), Institute of Public Finance (IPF). London, UK, 1997.

32. Emolun Hospital, Dept of Health, Paris, France, 1997.

33. New South Wales (NSW) Health Dept. Ambulatory Care Survey of Selected NSW (Public Hospitals: Outpatients Services), Structural and Funding Policy Branch, Sydney, Australia, 1997

34. Labour Force and Unpaid Work of Canadians. Statistics Canada, Ottawa, Canada, 1996. 
35. Direction de la Recherche des Etudes (DREES). France, 1999.

36. Andersson F, Ståhl E, Barnes PJ, et al., for the Formoterol and Corticosteroids Establishing Therapy (FACET) International Study Group. Adding formoterol to budesonide in moderate asthma: health economic results from the FACET study. Respir Med 2001; 95: 505-512.

37. Australian Bureau of Statistics. Canberra, Australia, August, 1999.

38. The Daily: Statistics Canada. Ottawa, Canada, 1999.

39. Institut National de la Statistique et des Etudes Economique (INSEE). Paris, France, 1997.

40. Encuesta de estruda salarial. Madrid, Instituto National de Estadistica (INE), Spain, 1995

41. Statistical yearbook of salaries (1997). Stockholm, Statistics Sweden, 1998.

42. The New Earnings Survey, part A, table 1. Office of National Statistics (ONS), London, UK, 1999.

43. Haddix AC, Teutsch SM, Shaffer PA, Dunet DO. Prevention effectiveness: a guide to decision analysis and prevention effectiveness. Oxford, Oxford University Press, 1996.

44. World Bank. World Development Indicators 2001. Washington DC, The World Bank, 2001.

45. Gerdtham U-G, Jönsson B. Convertion factor instability in international comparisons of health care expenditure J Health Econ 1991; 10: 227-234.

46. Gold MR, Siegel JE, Russell LB, Weinstein M. Costeffectiveness in Health and Medicine. New York, Oxford University Press, 1996.

47. Drummond MF, Bloom BS, Carrin G, et al. Issues in the cross-national assessment of health technology. Int J Technol Assess Health Care 1992; 8: 671-682.

48. Schulman KA, Buxton M, Glick H, et al. Results of the economic evaluation of the first study. A multinational prospective economic evaluation. Int $J$ Technol Assess Health Care 1996; 12: 698-713.

49. O'Brien BJ. A tale of two or more cities: geographic transferability of pharmacoeconomic data. Am J Man Care 1997; 3: S33-S39.

50. Jönsson B, Weinstein M. Economic evaluation alongside multinational clinical trials: study considerations for GUSTO IIb. Int J Technol Assess Health Care 1997; 13: 49-58.

51. Willke RJ, Glick HA, Polsky D, Schulman K. Estimating country-specific cost-effectiveness from multinational clinical trials. Health Econ 1998; 7: 481-493.

52. Koopmanschap MA, Touw KCR, Rutten FFH. Analysis of costs and cost-effectiveness in multinational trials. Health Policy 2001; 58: 175-186.

53. Rutten-van Mölken MPMH, van Doorslaer EKA, Jansen MC, Kerstjens HAM, Rutten FHF. Costs and effects of inhaled corticosteroids and bronchodilators in asthma and chronic obstructive pulmonary disease. Am J Respir Crit Care Med 1995; 151: 975-982.

54. Sullivan SD, Weiss KB, Lynn H, et al. The cost-effectiveness of an inner-city asthma intervention for children. $J$ Allegy Clin Immunol 2002; 110: 576-581.

55. Paltiel AD, Fuhlbrigge AL, Kitch BT, et al. Costeffectiveness of inhaled corticosteroids in adults with mildto-moderate asthma: results from the asthma policy model. J Allergy Clin Immunol 2001; 108: 39-46.

56. Chapman RH, Stone PW, Sandberg EA, Bell C, Neumann PJ. A comprehensive league table of cost-utility ratios and a sub-table of "panel-worthy" studies. Med Decis Making 2000; 20: 451-467.

57. Raftery J. NICE: faster access to modern treatments? Analysis of guidance on health technologies. BMJ 2001; 323: $1300-1303$. 